\title{
A NOTE ON CALOTARSA, AND DESCRIPTIONS OF TWO NEW SPECIES OF CALLIMYIA.
}

BY CHARLES W. JOHNSON, BOSTON, MASS.

Platypeza (Calotarsa) pallipes Loew.

The great variation in the two sexes of Platypeza has undoubtedly led to confusion that will take some time to straighten out. The relationship of a few have been suggested by Mr. Hugo Kahl in Professor Aldrich's catalogue, but that of $P$. velutina Loew and $P$. cinerea Snow does not seem to be quite clear. It was while trying to correlate the males and females that my attention was called to Platypeza pallipes Loew all females, taken at the same time and place as Calotarsa ornatipes Town. all males. The latter is not as rare as is generally supposed; I have recorded eighteen specimens, eleven of which are now before me together with nine specimens of $P$. pallipes. On September 3, 1897, while on North Mt., Pa. (above Stull) I captured almost in the same swing of the net $C$. ornatipes and $P$. pallipes. On September 5, 1903, Mr. Owen Bryant while on board the schooner "Sunshine" five miles east of the Isles of Shoals also collected a number of both. On September 24 and 28, 1903, six specimens of $P$. pallipes were taken on the windows of the museum of the Boston Society of Natural History, and on October 1 a dead specimen of $C$. ornatipes. That the two represent but one species is evident, as to Calotarsa I prefer to treat it as a subgenus. The bibliography and synonymy will stand as follows:

Platypeza pallipes Loew, Centur., VI, p. 81, 1865 . 우.

Calotarsa ornatipes Town., Can. Entom., XXVI, pp. 52, 102, 1894.

Platypeza ornatipes Banks, l.c. p. 88; Williston, l. c. p. 116; Snow, Kansas Univ. Quart., III, pp. 143, 207, pl. XII, fig. 2, 1894, 1895; Johnson, Ent. News, VII, p. 254, 1897; Greene, Ent. News, XIX, p. 241, 1908.

Platypeza (Calotarsa) ornatipes Johnson, Psyche, XI, p. 19, 1904.

Calotarsa ornatipes Aldrich, Ent. News, XVII, p. 123, pl. IV, fig. 2, 1906.

\section{Callimyia pulchella n. sp.}

ठ7 Face brownish, cheeks, occiput and frontal triangle black, with a slight grayish pollen; antennæ brownish black, third joint acutely conical, shorter than the arista. Thorax velvety black; scutellum orange yellow, base and basal angles narrowly margined with black, the four bristles long. Abdomen velvety black, with 
a wide band of orange yellow occupying the posterior half of the first segment, all of the second and the anterior two-thirds of the third except in the middle, where the black extends almost to the anterior margin; genitalia brownish black. Halteres black. Legs brownish, tarsi black, the hind metatarsi normally thickened. Wings hyaline. Length, $2.5 \mathrm{~mm}$.

ㅇ Front grayish pollinose. Thorax dull black, brownish on the posterior portion; scutellum and halteres bright yellow. First three segments entirely yellow, the discal portion of the fourth and part of the fifth grayish pollinose, terminal segment yellowish. Legs also yellow.

Three $\sigma^{\top}$ and one $q$, collected by the writer along a tributary of the Passumpsic River, at St. Johnsbury, Vermont, June 27 and 28, 1906. Types in the collection of the Boston Society of Natural History.

Callimyia fulva n. $\mathrm{sp.}$

o Front and face blackish, pruinose, occiput deep black, cheeks palpi antennæ and ocelli yellow; third joint of the antenna attenuated, longer than the arista. Thorax and scutellum fulvous, and bearing the following black bristles: one humeral, five notopleural arranged transversely, the lower one much smaller than the others, two intra-alar, two dorsocentral in front of the scutellum and six large scutellar bristles; there are also three dorsal rows of small black hairs the outer rows curving towards the humeri. Abdomen and halteres also fulvous, the pleurae and legs light yellow, wings hyaline, veins yellow, costae brown, with three black bristles at the base. Length, $3 \mathrm{~mm}$.

One specimen collected by writer at Capens, Deer Island, Moosehead Lake, Maine, July 19, 1907, Type in the Boston Society of Natural History.

Callimyia talpula Loew.

Callomyia talpula Loew, Centur., IX, 81, 1869.

This species was based on a female taken in New Hampshire. It is velvety black, with yellow legs. Two specimens of the male, one collected in Mt. Greylock, Mass., June 15, 1906, the other at Auburndale, Mass., August 16, agree with Loew's description, and type; the sexual characters are therefore all that need be described. The posterior metatarsi are very broad and almost ovate, the posterior tibiæ are also greatly dilated and as broad as the metatarsi; the genitalia prominent and brownish black. Length, $2.5 \mathrm{~mm}$. 

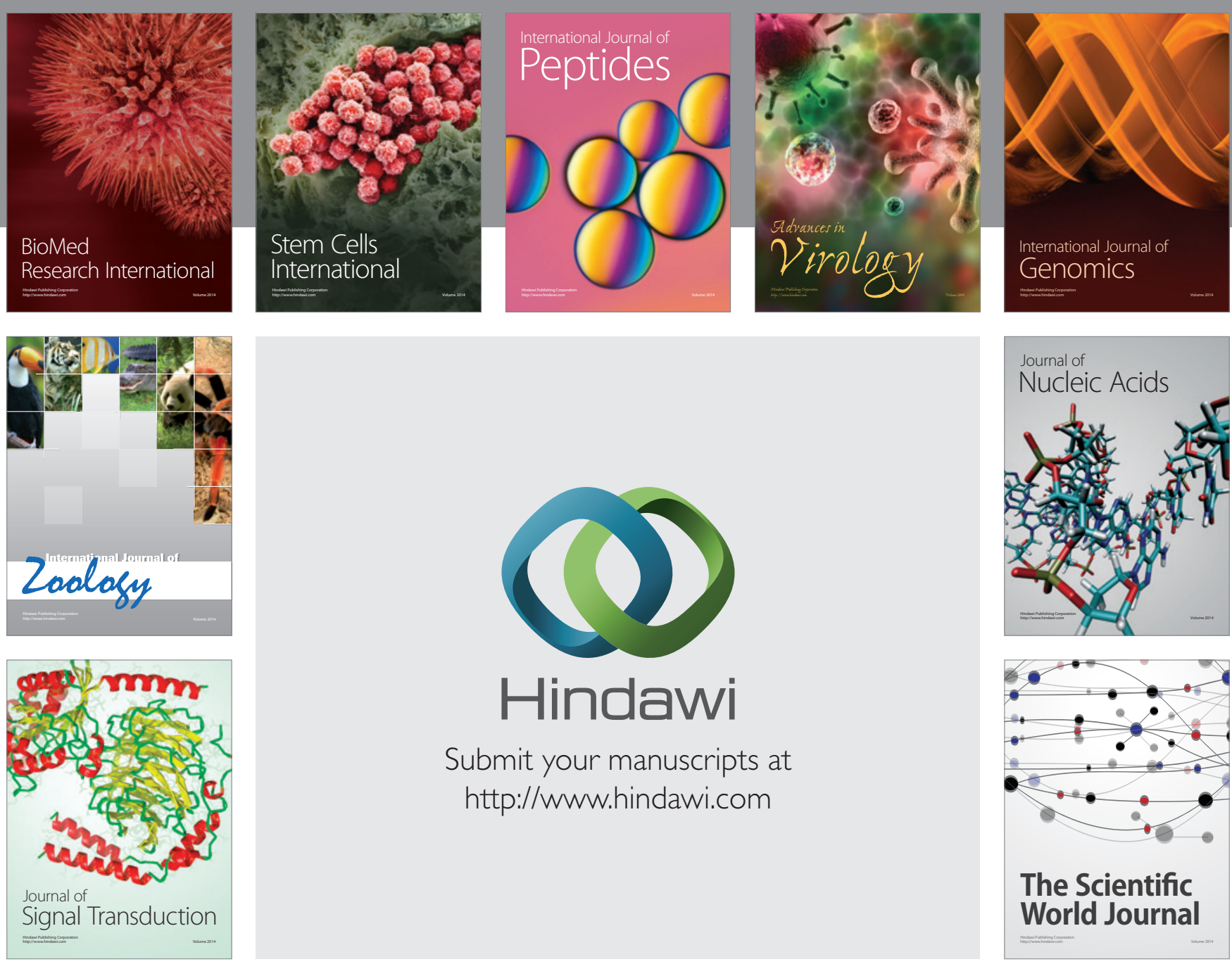

Submit your manuscripts at

http://www.hindawi.com
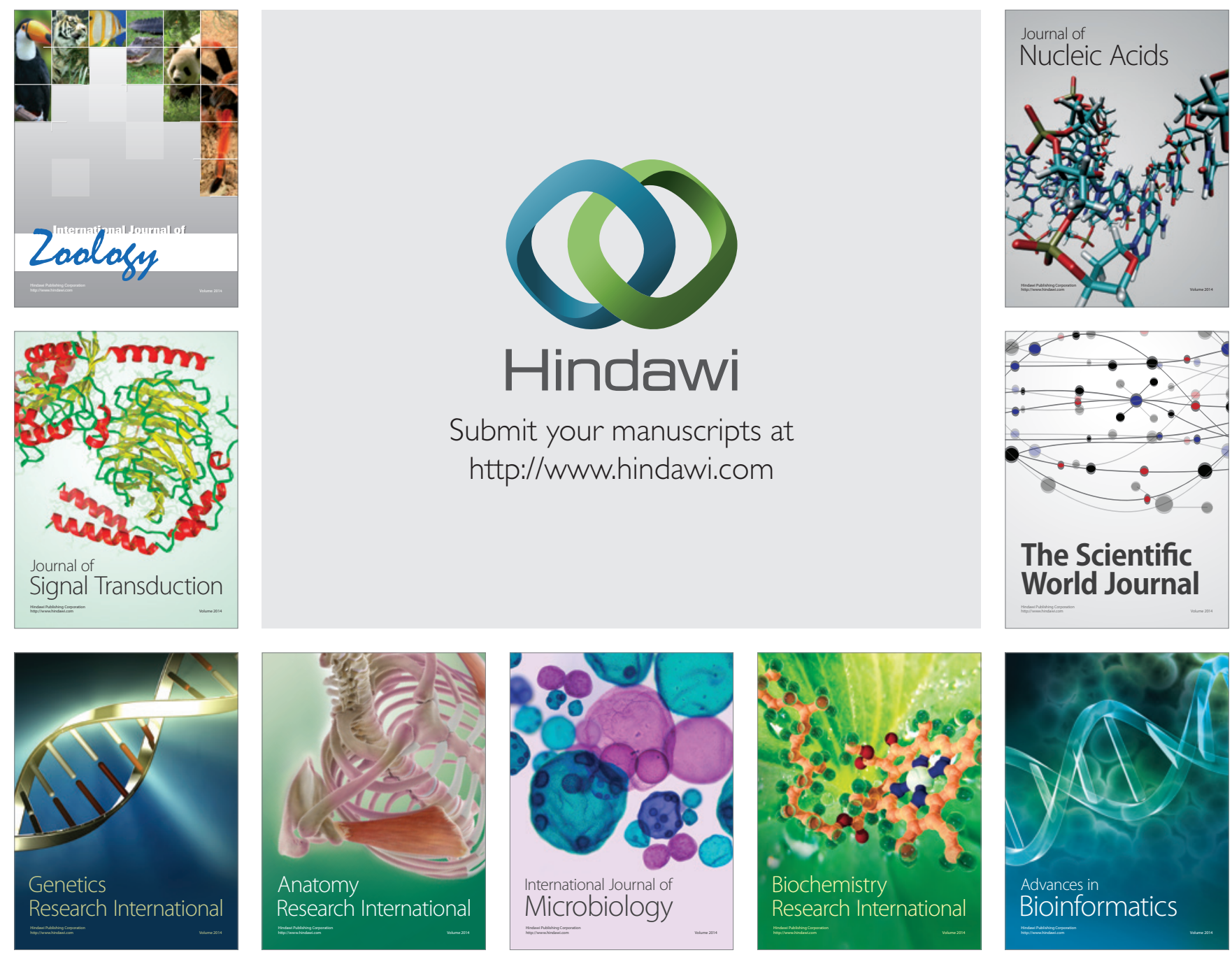

The Scientific World Journal
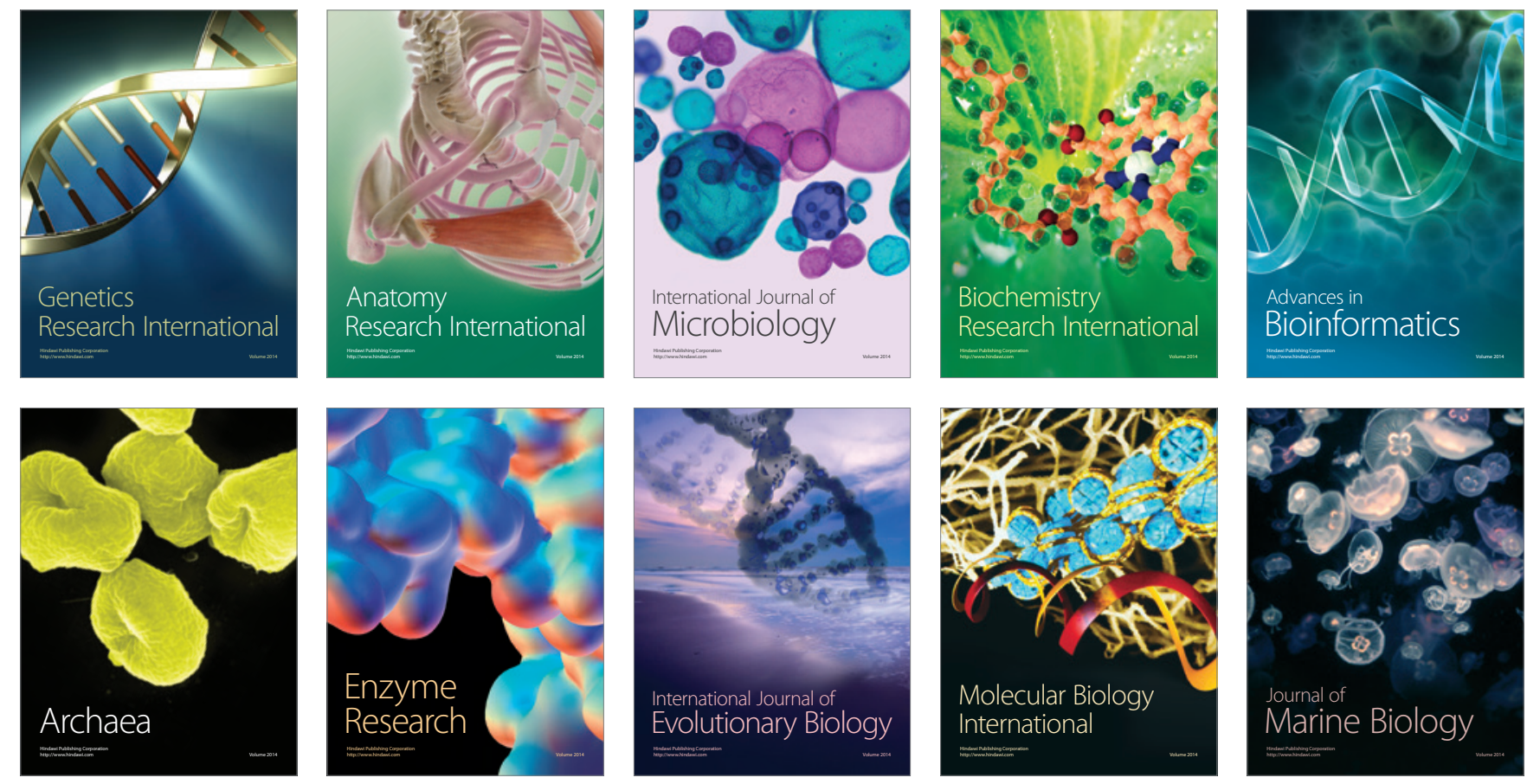